\title{
Circulating biomarkers in the early detection of hypertensive heart disease: usefulness in the developing world
}

\author{
Dike Ojji ${ }^{1}$, Elena Libhaber ${ }^{2}$, Kim Lamont $^{2}$, Friedrich Thienemann ${ }^{3,4,5}$, Karen Sliwa ${ }^{2,3}$ \\ ${ }^{1}$ Cardiology Unit, Department of Medicine, University of Abuja Teaching Hospital, Abuja, Nigeria; ${ }^{2}$ Soweto Cardiovascular Research Unit, \\ University of Witwatersrand, Johannesburg, South Africa; ${ }^{3}$ Hatter Institute for Cardiovascular Research in Africa, Department of Medicine and \\ Cardiology, Faculty of Health Sciences, University of Cape Town, Cape Town, South Africa; ${ }^{4}$ Department of Internal Medicine, University Hospital \\ Zurich, University of Zurich, Zurich, Switzerland; ${ }^{5}$ Wellcome Centre for Infectious Diseases Research in Africa, Institute of Infectious Disease and \\ Molecular Medicine, Faculty of Health Sciences, University of Cape Town, Cape Town, South Africa \\ Contributions: (I) Conception and design: D Ojji; (II) Administrative support: K Lamont, E Libhaber; (III) Provision of study materials or patients: \\ D Ojji, E Libhaber; (IV) Collection and assembly of data: All authors; (V) Data analysis and interpretation: All authors; (VI) Manuscript writing: All \\ authors; (VII) Final approval of manuscript: All authors. \\ Correspondence to: Dike Ojji. Cardiology Unit, Department of Medicine, University of Abuja Teaching Hospital, Abuja. Email: dike.ojji@uniabuja.edu.ng.
}

\begin{abstract}
Although the varying phenotypic spectra of hypertensive heart disease (HHD) can be assessed by electrocardiography (ECG), echocardiography and cardiovascular magnetic resonance (CMR), ECG criteria for left ventricular hypertrophy $(\mathrm{LVH})$ are insensitive, while echocardiography and CMR are expensive, less readily available and often lack requisite expertise. Consequently, the use of circulating biomarkers in the diagnosis and prognostication of HHD beyond the traditional N-terminal pro- b-type natriuretic peptide (NT-proBNP) and B-type natriuretic peptide (BNP) have become an attractive alternative. We carried out a PubMed and Google Scholar databases' search of original articles on circulating biomarkers used in the diagnosis of the different spectrum of HHD over the last 10 years [2005-2015] in humans. Fourteen studies met the inclusion criteria with NT-pro BNP being the most studied circulating biomarker in HHD followed by soluble ST2 (sST2). There is a lack of data on the use of circulating biomarkers in HHD. There is a need to explore further this area of investigative cardiology.
\end{abstract}

Keywords: Role; circulating biomarkers; hypertensive heart disease (HHD)

Submitted May 27, 2019. Accepted for publication Sep 03, 2019.

doi: $10.21037 /$ cdt.2019.09.10

View this article at: http://dx.doi.org/10.21037/cdt.2019.09.10

\section{Introduction}

Hypertension (HT) is the leading single risk factor for cardiovascular events and deaths worldwide (1). It is projected that the total number of people affected by HT will increase to about 1.56 billion in 2025 (2) Sub-Saharan Africa (SSA) is particularly affected by this epidemic, and will witness the greatest increase in disease burden (2). The consequences of HT vary from congestive cardiac failure, chronic kidney disease, cerebrovascular accidents, vascular dementia, cardiovascular mortality and sudden death (3-5).

One of the main complications of HT is hypertensive heart disease (HHD), representing the accumulation of structural and functional adaptations to increased blood pressure load on the heart (6). Features of this condition are left ventricular hypertrophy (LVH), increased vascular and ventricular stiffness and impaired LV filling which ultimately lead to heart failure, if not adequately treated (6).

Although LVH can be assessed by electrocardiography (ECG) and echocardiography, ECG criteria for LVH generally have low sensitivity even though there have been some improvements in its diagnostic accuracy especially in obesity (7). On the other hand echocardiography results may be of poor quality, and more so in patients with obesity or pulmonary disease $(8,9)$ This has led to accelerated research on the use of circulating biomarkers to assist as diagnostic and prognostic tools in HHD apart from the traditional biomarkers 


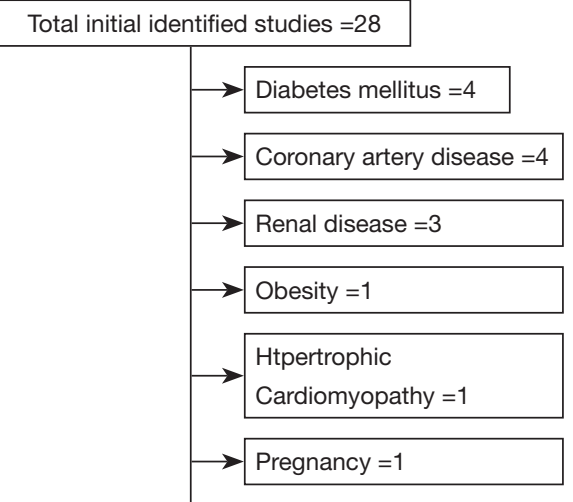

Included studies $=14$

Figure 1 Flow chart of study section.

like B-type natriuretic peptide (BNP) and N-terminal prob-type natriuretic peptide (NT-proBNP) (10).

\section{Search strategy}

This literature review followed all the guidelines set out by the Preferred Reporting Items for Systematic reviews and Meta-Analyses (PRISMA) statement for articles of this nature. In order to ensure a comprehensive and current appraisal of the use of circulating biomarkers in the spectrum of HHD we considered articles on human studies published between 2005 and 2015. We excluded all studies which focused on HT as a secondary factor and not as a primary factor. We reviewed the abstracts of all potentially relevant paper while full articles were accessed through PubMed and Google Scholar. There was careful scrutiny of the references of all the relevant research articles for possible additional data sources while the full texts of these studies were then similarly accessed.

We also carried out an exploration of bibliographies cited in the identified articles to provide further studies. We obtained full texts of the articles from various online sources. And we used a data extraction sheet to collect the information on year of publication, the primary disease condition studied, and the circulating biomarker used.

Figure 1 shows the schematic diagram of how the process of choosing the studies that were included in the review was carried out. Twenty-eight studies on the use of BNP or NT-ProBNP, soluble ST2 (sST2) and cardiotrophin-1 in the diagnosis of the spectrum of HHD were identified by PubMed. We excluded four studies on diabetes mellitus, another four studies on coronary artery disease, two studies on renal disease and one study on obesity, hypertrophic cardiomyopathy and pregnancy, respectively.

\section{NT-ProBNP in HHD}

$\mathrm{LVH}$ has been reported as one of the conditions in which plasma BNP and NT-ProBNP significantly exceed the normal range (11). Plasma NT-ProBNP level has been found has been found to rise progressively with increasing severity of HT particularly when VH is present (11). and to be a useful marker of LVH. In a similar way, it has been shown that plasma BNP and NT-ProBNP levels are useful to differentiate between patients with different spectrum of cardiac remodelling (12), and should be considered as screening tools to select hypertensive patients that should undergo a detailed echocardiographic examination. Furthermore, in a recent study, NT-proBNP was found to be an independent predictor of survival in hypertensive patients and increased LV mass (11). Other workers have however found that even though NT-ProBNP is useful in differentiating hypertensive patients with or without $\mathrm{LVH}$ from hypertensive heart failure (HHF), it is not the best marker for differentiating hypertensive subjects with LVH from those without LVH $(13,14)$. Our group has corroborated these observations (14); among 210 black African hypertensive subjects (83 hypertensives without LVH, 50 hypertensives with LVH and 77 HHF subjects). In this study, subjects with HHF had significantly higher levels of NT-ProBNP compared to hypertensive subjects with or without LVH $(\mathrm{P}<0.002)$. There was, however, no difference in the levels of NT-ProBNP between hypertensive subjects with LVH and those without LVH (Figure 2). And similar to a previous study (15), NT-ProBNP did not correlate with LV mass index, interventricular septal wall thickness and LV posterior diastolic wall thickness. We however found that NT-ProBNP correlated significantly with mean arterial pressure, pulse pressure and age, supporting previous studies $(16,17)$ with renal impairment (18).

\section{Novel biomarkers in HHD}

The limitation of NT-ProBNP in differentiating the various spectra of HHD has led to research for the discovery of biomarkers of superior usefulness for the clinical handling of HT evolving to HHD and HHF (19). A number of the biochemical markers that have been studied include cardiotrophin-1, ST2, annexin A5, carboxy-terminal propeptide of pro collagen type 1 , matrix metalloproteinase-1 


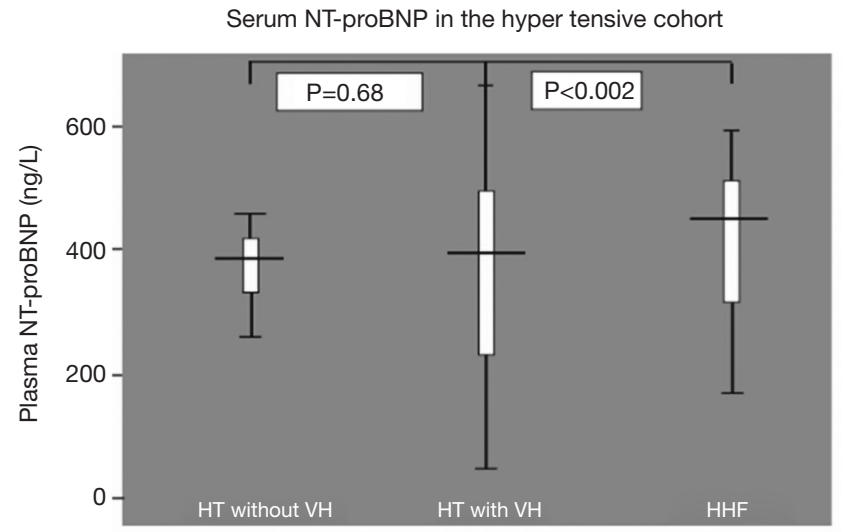

Figure 2 Box plot comparing NT-proBNP levels in patients with HT without $\mathrm{VH}$, to patients with $\mathrm{HT}$ with $\mathrm{VH}$, and patients with HHF. NT-proBNP, N-terminal pro- b-type natriuretic peptide; HT, hypertension; VH, ventricular hypertrophy; HHF, hypertensive heart failure.

(MMP-1) and galectin-3. ST2 and cardiotrophin-1 are more frequently studied in cardiovascular disease (CVD) compared to the rest.

\section{Cardiotrophin-1}

Cardiotrophin-1 appears to be one of the most promising biomarkers for criteria which includes relationship between its expression in the myocardium and its level in the blood, a positive gradient from its concentration in coronary sinus blood towards its concentration in peripheral veins, association between the concentration in the blood with cardiac structural and functional parameters and variation of levels of the biomarker with cardiac structural and functional changes induced by pharmacological therapy (19). Cardiotrophin- 1 is a cytokine member of the interleukin-6 super family, which is produced by cardiomyocytes and cardiac fibroblasts in situations of biochemical stress and under exposure to humoral factors such as angiotensinII $(20,21)$. Once secreted, it interacts with its receptor, which is a heterodimer formed by glycoprotein-130 and the leukaemia inhibitory factor receptor activating different signalling pathways thereby leading to cardiomyocyte growth dysfunction (22). Plasma cardiotrophin-1 concentration has been found to be increased in hypertensive patients as a whole group, compared to normotensive subjects $(23,24)$. It has also been reported that plasma cardiotrophin-1 is higher in patients with $\mathrm{LVH}$ than in patients without $\mathrm{LVH}$ (25), and in patients with heart failure than in patients with $\mathrm{LVH}$ (26).
In addition, it has been found out that $31 \%$ of hypertensive patients without LVH already exhibited concentrations of cardiotrophin-1 abnormally elevated above the upper normal limit measured in the normotensive control population which suggests that cardiotrophin-1 increases early in the evolution of arterial HT (27). An association exists between antihypertensive-induced decrease of plasma cardiotrophin-1 and reduction of $\mathrm{LV}$ mass index in patients with $\mathrm{LVH}$ (28). Abnormally high plasma cardiotrophin-1 concentration is associated with reduced fractional shortening and altered relaxation in patients with inappropriate LV mass (29). Lastly, cardiotrophin-1 presents an acceptable sensitivity of $70 \%$ and specificity of $75 \%$ to detect $\mathrm{LVH}$, as assessed by echocardiography in hypertensive patients (29).

\section{SST2}

The most recent novel circulating biomarker that has been tested in differentiating the various spectrum of HHD is SST2. ST2 receptor is a member of the Toll-like/ interleukin-1 receptor family. Research in animal models have shown that cytokine IL-33 interacts with ST2 receptors in cardiac myocytes, thereby comprising a cardioprotective stress-responsive signalling system (19). ST2 exists in two forms-transmembrane and soluble forms. sST2 is a candidate biomarker in CVD. Mice treated with exogenous IL-33 demonstrate reduced hypertrophy, and transgenic deletion of ST2 abolishes this potentially adaptive effect, thereby resulting in severe myocardial hypertrophy and fibrosis (19). In response to inflammation and cardiac stress IL-33/ST2 signalling becomes activated and the soluble form of ST2 is released into the circulation (Figure 3). sST2 acts as a decoy receptor, sequestering and inhibiting IL-33 and this potentially explains why it has been observed that higher circulating levels reflect increased cardiac risk (30). Mechanistic studies identified ST2 as a gene markedly induced in mechanically overloaded cardiac myocytes $(31,32)$. sST2 is induced in conditions of myocardial overload, such as myocardial infarction, when the remaining viable myocardium must bear more stress (31). sST2 has been found to be increased in the serum of patients one day after acute myocardial infarction (AMI) (32). In addition, sST2 levels have been shown to predict outcome in patients with heart failure and a change in SST2 over time is also associated with poorer prognosis (32). Although the lung has been shown to have the highest expression of sST2 levels (33), potential cellular sources of sST2 in the cardiovascular system include endothelial cells 


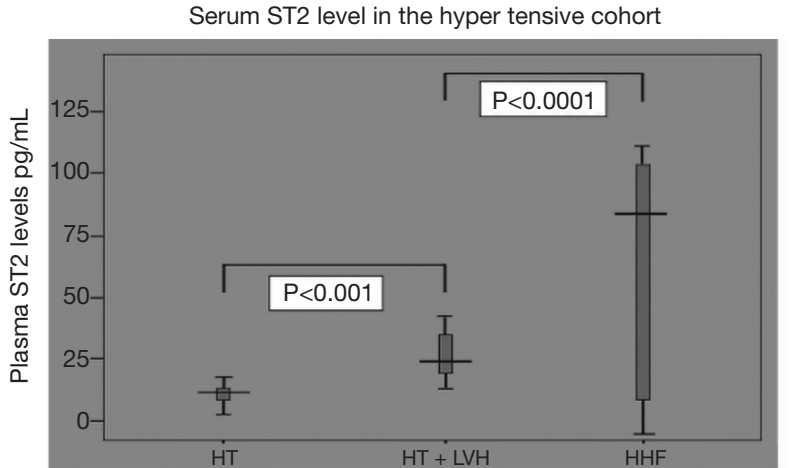

Figure 3 Box plot comparing soluble ST2 levels in patients with HT, to patients with HT with LVH, and patients with HHF. HT, hypertension; $\mathrm{VH}$, ventricular hypertrophy; LVH, left ventricular hypertrophy; HHF, hypertensive heart failure.

\section{$(34,35)$ and cardiac myocytes (33).}

The first study to show that sST2 level was elevated early after AMI was carried out in 69 human samples and showed that sST2 levels correlated with creatinine kinase and correlated inversely with LV ejection fraction (LVEF) (31). Two larger studies have demonstrated the prognostic value of measuring sST2 in AMI. Aoki et al. (36) measured sST2 in 810 patients with AMI in the Thrombolysis In Myocardial Infarction (TIMI)-14 and Enoxaparin and TNK-tPA with or without Glycoprotein IIb/IIIa (GPIIb/IIIa) inhibitor as Reperfusion Strategy in STEMI(ENTIRE)-TIMI-23 clinical trials. They demonstrated that baseline levels of sST2 were higher in patients who died or developed congestive heart failure. sST2 levels were also measured in 1,239 patients from the Clopidogrel as Adjunctive Reperfusion Therapy Thrombolysis in Myocardial Infarction 28 (CLARITY-TIMI 28) trial (36). The authors found that high levels of sST2 at baseline were a significant predictor of cardiovascular mortality and heart failure and combined measurement of ST2 and NT-proBNP significantly improved prediction of cardiovascular death. Measurement of sST2 early after AMI in 100 patients undergoing cardiovascular magnetic resonance (CMR) also predicted adverse LV functional recovery and remodeling (37). In an outpatient study, sST2 levels also reflected right ventricular heart size and function, and were an independent predictor of one-year mortality in outpatients referred for echocardiography (38).

Several other studies have reported similar findings: sST2 levels correlated with severity of heart failure, LVEF, creatinine clearance, BNP, C-reactive protein, and were a predictor of mortality (39-42). Concentrations of sST2 have also been found to be predictive of mortality in dyspnoea patients with and without acutely decompensated heat failure (43-46). In addition, cardiac surgery patients undergoing coronary artery bypass grafting with cardiopulmonary bypass demonstrate a significant rise in sST2 levels 24 h after surgery (47). In conclusion, these studies indicate that $\mathrm{sST} 2$ has potential to be a predictive cardiovascular biomarker in patients with AMI, heart failure and dyspnoea, but further studies are required.

\section{SST2 as a novel biomarker in HHD}

In spite of the use of $\mathrm{sST} 2$ as a marker in the field of cardiovascular medicine, there are very few studies on the use of sST2 in HHD $(48,49)$. We could demonstrate in our laboratory in a sample of 210 black hypertensive patients that sST2 differentiates the various stages of HHD, with heart failure patients having higher concentrations of sST2 compared to hypertensive patients with $\mathrm{LVH}(\mathrm{P}<0.001)$ or without LVH $(\mathrm{P}<0.0001)$, and patients with HT and LVH having higher concentration of sST2 compared to those without LVH (Figure 3) (50). The sensitivity and specificity of differentiating HT without LVH from hypertensive heart failure were $76.5 \%$ and $100 \%$, respectively, with a cut-off value of $38.01 \mathrm{ng} / \mathrm{mL}$ while the sensitivity and specificity of distinguishing HT with LVH from HHF were $82.4 \%$ and $100 \%$, respectively, with a cut-off value of $24.97 \mathrm{ng} / \mathrm{mL}$. On the other hand, the sensitivity and specificity of distinguishing HT with LVH from HT with $\mathrm{LVH}$ were $87 \%$ and $56 \%$, respectively, with a cut-off value of $14.45 \mathrm{ng} / \mathrm{mL}$. We also found pulse pressure, LV internal diameter in systole, LV mass indexed for height and LVEF to be independent co-variants of sST2 concentrations. We concluded in our study as depicted in Figures 3,4 that sST2 is a better biomarker when compared to NT-ProBNP in this regard. We also found in a cohort of 133 patients without heart failure that sST2 was not only higher in those with $\mathrm{LVH}$ compared with those without $\mathrm{LVH}(23.0 \pm 8.33 \mathrm{ng} / \mathrm{mL}$ versus $14.5 \pm 4.9 \mathrm{ng} / \mathrm{mL}, \mathrm{P}<0.001)$, but patients with concentric hypertrophy had the highest concentration of sST2 compared to normal geometry, concentric remodelling and eccentric hypertrophy (51).

\section{Other less studied novel biomarkers in CVD}

\section{Annexin A5}

Annexin A5 is a $32-35 \mathrm{KDa}$ calcium binding protein that 


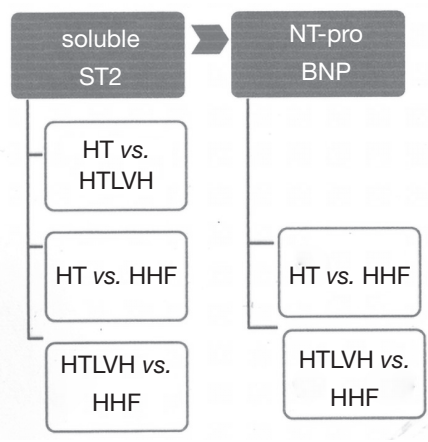

Figure 4 Schematic diagram comparing cardiac blood biomarkers soluble ST2 and NT-ProBNP in hypertensive heart disease. Soluble ST2, but not NT-ProBNP, may distinguish HT from HT with LVH (HTLVH) and absent heart failure. NT-proBNP, $\mathrm{N}$-terminal pro- b-type natriuretic peptide; HT, hypertension; $\mathrm{VH}$, ventricular hypertrophy; LVH, left ventricular hypertrophy; HHF, hypertensive heart failure; NT-proBNP, N-terminal pro-btype natriuretic peptide.

becomes upregulated in response to apoptosis $(52,53)$. The expression of annexin A5 has been found to be abnormally increased in the myocardium of hypertensive patients with LVH exhibiting increased apoptosis of cardiomyocytes (54), suggesting its potential as biomarker in monitoring the progression of HT to HHF. The pathway of the secretion and action of annexin A5 is closely related to the pathway of cardiotrophin-1.

\section{Carboxy-terminal propeptide of procollagen type I}

Carboxy-terminal propeptide of procollagen type I is a peptide that is cleaved from procollagen type I during the extracellular synthesis of fibril-forming collagen type I carboxy-terminal proteinase. It is, therefore, a biochemical marker related to the collagen matrix. It has been found to be associated with volume of myocardial tissue occupied by collagen fibres both in spontaneously hypertensive rats with LVH (55) and hypertensive LVH in human subjects $(56,57)$. It has also been shown that serum carboxyterminal propeptide procollagen type $\mathrm{I}$ is elevated in hypertensive patients when compared with normotensive subjects $(58,59)$, but no significant differences in the levels between hypertensive patients with or without LVH similar to our finding using NT-proBNP as the biomarker. However, higher concentrations of carboxyterminal propeptide procollagen type I have been found in hypertensive heart failure when compared with hypertensive LVH (60).

\section{Ratio of MMP-1/tissue inhibitor of metalloproteinases-1 (TIMP-1)}

The interaction between MMP-1 that initiates the degradation of collagen fibres within the heart and its TIMP-1 has been found to hold some promise in assessing HHD. The ratio of MMP-1/TIMP-1 has been found to be abnormally increased in subjects with HHF and abnormally decreased in patients with HT with or without $\mathrm{LVH}(61,62)$. This ratio is higher in hypertensive patients with systolic heart failure than in patients with diastolic heart failure. Therefore, it is suggested that the determination of MMP-1 and TIMP-1 in serum might be a useful biochemical marker of systolic deterioration and geometric dilatation of the LV chamber in HHF (63). This finding is corroborated by the study of Maharaj et al. in the study of 82 subjects of African descent with HT (41 with LVEF $\geq 50 \%$ and the other 41 with LVEF <50\%) who showed that TIMPI-1, MMP-1 and the ratio of MMP-1/TIMPI-1 were higher in the subjects with reduced LVEF compared to those with normal LVEF (64).

\section{Galectin-3}

Galectin-3 is beta-galactoside-binding lectin which is expressed by activated macrophages, and involved in numerous pathological processes including inflammation, fibrosis and tumour growth (65). In heart failureprone animals, galactin-3 is markedly up regulated in decompensated heart failure and increased galectin-3 expression induces cardiac fibroblasts to proliferate and deposit type I collagen, thereby contributing to myocardial fibrosis and adverse remodeling (66). These findings have made galectin-3 to be linked in the development of heart failure (66). A recent study shows that the levels of galectin-3 are higher in patients with both $\mathrm{HT}$ and diabetes compared with those with HT or diabetes alone. These levels also correlated with LV mass (67).

\section{Discussion}

\section{Clinical implications of circulating biomarkers for the management of HHD}

The effectiveness of a novel biomarker in clinical practice depends on the consistency and strength of the association between the candidate biochemical marker for a given disease, the consistency and strength of the association between the biochemical marker and the outcome of the disease, and the extent to which it is an improvement on 
either adding or replacing established conventional markers like NT-ProBNP.

Therefore, our findings of sST2 as a biomarker that does not only complement NT- proBNP but performs better in differentiating the different spectra of HT and HHD has set the stage for larger clinical trials wherein sST2's role could be demonstrated as superior biomarker when compared with NT-ProBNP in the early detection of hypertensive patients at risk of developing $\mathrm{LVH}$, identification of hypertensive patients with $\mathrm{LV}$ prone to evolve to heart failure and identification of hypertensive patients with HF that will exhibit progressive deterioration of cardiac performance. The importance of this type of biomarker that will help in the early detection of the complication of HT cannot be over emphasized. In SSA, understanding the progression of HT to HHD and early detection of this process is critical to minimizing CVD in this region $(68,69)$. An important test performance for early detection can be achieved in this region with limited resources only as pointof-care blood (or urine) biomarker test. In addition, such point-of-care test would need to be significantly cheaper and more broadly available when compared to conventional investigations like ECG and echocardiography. In the current situation, conventional biomarkers cost about twice as much as echocardiography in Nigeria, for example, will limit the use of such biomarkers in a population with very low health insurance coverage, and where most health spending by patients is being "out-of-pocket".

\section{Conclusions}

The importance of a biomarker that differentiates uncomplicated cases of HT from those at risk or present major cardiac complications cannot be over-emphasized in settings like SSA with high burden of HHD (70), where imaging modalities such as echocardiography, CT and CMR are inaccessible for most of the population. However, for such a biomarkers like ST2 to be integrated into clinical decision making protocols for hypertensive patients, large epidemiological and clinical studies will be required to assess the cost-effectiveness of such a marker compared to conventional ECG and echocardiography. And finally its precision to predict outcomes needs to be scrutinized.

\section{Acknowledgments}

We sincerely appreciate all members of staff of Cardiology Unit, Department of Medicine, University of Abuja
Teaching Hospital, Abuja, Nigeria and Hatter Institute for Cardiovascular Research, Department of Medicine, Faculty of Health Sciences for all the support.

Funding: None.

\section{Footnote}

Provenance and Peer Review: This article was commissioned by the Guest Editor (Ntobeko A. B. Ntusi) for the series "Cardiovascular Diseases in Low-and Middle-Income Countries" published in Cardiovascular Diagnosis and Therapy. The article was sent for external peer review organized by the Guest Editor and the editorial office.

Conflicts of Interest: All authors have completed the ICMJE uniform disclosure form (available at http://dx.doi. org/10.21037/cdt.2019.09.10). The series "Cardiovascular Diseases in Low- and Middle-Income Countries" was commissioned by the editorial office without any funding or sponsorship. The authors have no other conflicts of interest to declare.

Ethical Statement: The authors are accountable for all aspects of the work in ensuring that questions related to the accuracy or integrity of any part of the work are appropriately investigated and resolved.

Open Access Statement: This is an Open Access article distributed in accordance with the Creative Commons Attribution-NonCommercial-NoDerivs 4.0 International License (CC BY-NC-ND 4.0), which permits the noncommercial replication and distribution of the article with the strict proviso that no changes or edits are made and the original work is properly cited (including links to both the formal publication through the relevant DOI and the license). See: https://creativecommons.org/licenses/by-nc-nd/4.0/.

\section{References}

1. Lim SS, Vos T, Flaxman AD, et al. A comparative risk assessment of burden of disease and injury attributable to 67 risk factors and risk factor clusters in 21 regions, 1990-2010: a systematic analysis for the Global Burden of Disease Study 2010. Lancet 2012;380:2224-60.

2. Kearney PM, Whelton M, Reynolds K, et al. Global burden of hypertension: analysis of worldwide data. Lancet 2005;365:217-23.

3. Benetos A, Thomas F, Bean K, et al. Prognostic value of 
systolic and diastolic blood pressure in treated hypertensive men. Arch Intern Med 2002;162:577-81.

4. Lewington S, Clarke R, Qizilbash N, et al. Age-Specific relevance of usual blood pressure to vascular mortality: a meta-analysis of individual data for one million adults in 81 prospective studies. Lancet 2002;360:1903-13.

5. Miniño AM, Murphy SL, Xu J, et al. Deaths: final data for 2008. Natl Vital Stat Rep 2011;59:1-126.

6. Izzo JL, Grandman AH. Mechanisms and management of hypertensive heart disease: from left ventricular hypertrophy to heart failure. Med Clin N Am 2004;88:1257-71.

7. Rider OJ, Ntusi N, Bull SC, et al. Improvements in ECG accuracy for diagnosis of left ventricular hypertrophy in obesity. Heart 2016;102:1566-72.

8. Devereux RB, Casale PN, Eisenberg RR, et al. Electrocardiographic detection of left ventricular hypertrophy using echocardiographic determination of left ventricular mass as the reference standard: comparison of standard criteria, computer diagnosis and physician interpretation. J Am Coll Cardiol 1984;3:82-7.

9. Ceyhan C, Unal S, Yenisey C, et al. Increased plasma concentrations of $\mathrm{N}$-terminal pro-brain natiuretic peptide reflect the presence of mildly reduced left ventricular diastolic function in hypertension. Int J Cardiovasc Imaging 2008;24: 253-9.

10. Irzmanski R, Barylski M, Banach $M$, et al. The concentration of atrial and brain natriuretic peptide in patients with idiopathic hypertension. Med Sci Monit 2007;13:CR449-56.

11. Vaĭda LS, Lozyns'ka NV. [The relation of structural and functional status of the left chambers of the heart, the level of circulating NT-pro-BNP and the status of endothelium dependent vasodilation with characteristics of 24 hour blood pressure monitoring in patients with arterial hypertension]. Lik Sprava 2013;(3):16-24.

12. Santosa YP, Tjandrawati A, Martanto E, et al. Comparison of pro-B-natriuretic Peptide in Hypertensive Patients with and without Diastolic Dysfunction. Acta Med Indones 2008;40:19-23.

13. Barutçuoglu B, Parildar Z, Başol G, et al. The detection of left ventricular diastolic dysfunction in hypertensive patients: Performance of $\mathrm{N}$-terminal probrain natriuretic peptide. Blood Press 2010;19:212-7.

14. Ojji DB, Opie LH, Lecour S, et al. The proposed role of Plasma NT pro-brain natiuretic peptide in assessing cardiac remodelling in hypertensive African subjects. Cardiovasc J Afr 2014;5:233-8.
15. Irzmański R, Banach $M$, Piechota $M$, et al. Atrial and brain natriuretic peptide and endothelin-1 concentration in patients with idiopathic arterial hypertension: the dependence on the selected morphological parameters. Clin Exp Hypertens 2007;29:149-64.

16. Pemberton CJ, Raudsepp SD, Yandle TG, et al. Plasma cardiotrophin-1 is elevated in human hypertension and stimulated by ventricular stretch. Cardiovasc Res 2005;68:109-17.

17. Wang TJ, Larson MG, Levy D, et al. Impact of age and sex on plasma natriuretic peptide levels in healthy adults. Am J Cardiol 2002;90:254-8.

18. Furumoto T, Fujii S, Mikami T, et al. Increased plasma concentrations of $\mathrm{N}$-terminal pro-brain natriuretic peptide reflect the presence of mildly reduced left ventricular diastolic function in hypertension. Coron Artery Dis 2006; $17: 45-50$.

19. López B, Castellano JM, González A, et al. Association of increased plasma cardiotrophin-1 with inappropriate left ventricular mass in essential hypertension. Hypertension 2007;50:977-83.

20. González A, López B, Ravassa S, et al. Biochemical markers of myocardial remodelling in hypertensive heart disease. Cardiovasc Res 2009;81:509-18.

21. Kuwahara K, Saito Y, Harada M, et al. Involvement of cardiotrphin-1 in cardiac myocyte-nonmyocyte interactions during hypertrophy of rat cardiac myocytes in vitro. Circulation 1999;100:1116-24.

22. Sano M, Fukuda K, Kodama H, et al. Interleukin-6 family of cytokines causes angiotensin II-induced delayed STAT 3 activation. Biochem Biophys Res Commun 2000;269:798-802.

23. Pennica D, Wood WI, Chien KR. Cardiotrophin-1: a multifunctional cytokinethat signals via LIF receptor-gp 130 dependent pathways. Cytokine Growth Factor Rev 1996:7:81-91.

24. López N, Díez J, Fortuño MA. Differential hypertrophic effects of cardiotrophin-1 on adult cardiomyocytes from normotensive and spontaneously hypertensive rats. J Mol Cell Cardiol 2006;41:902-13.

25. Pemberton CJ, Johnson ML, Yandle TG, et al. Deconvolution analysis of cardiac natriuretic peptides during acute volume overload. Hypertension 2000;36:355-9.

26. López B, González A, Lasarte JJ, et al. Is plasma cardiotrophin-1 a marker of hypertensive heart disease? J Hypertens 2005;23:625-32.

27. Asai S, Saito Y, Kuwahara K, et al. The heart is a source of 
circulating cardiotrophin-1 in humans. Biochem Biophys Res Commun 2000;279:320-3.

28. González A, Ravassa S, Loperena I, et al. Association of depressed cardiac gp130-mediated antiapoptotic pathways with stimulated cardiomyocyte apoptosis in hypertensive patients with heart failure. J Hypertens 2007;25:2148-57.

29. González A, López B, Martín-Raymondi D, et al. Usefulness of plasma cardiotrophin-1 in assessment of left ventricular hypertrophy regression in hypertensive patients. J Hypertens 2005;23:2297-304.

30. Sanada S, Hakuno D, Higgins LJ, et al. IL-33 and ST2 comprise a critical biomechanically induced and cardio protective signaling system. J Clin Invest 2007;117:1538-49.

31. Kakkar R, Lee RT. The IL-33/ST 2 pathway: therapeutic target and novel biomarker. Nat Rev Drug Discov 2008;7:827-40.

32. Weinberg EO, Shimpo M, De Keulenaer GW, et al. Expression and regulation of ST2, an interleukin-1 receptor family member, in cardiomyocytes and myocardial infarction. Circulation 2002;106:2961-6.

33. Weinberg EO, Shimpo M, Tominaga S, et al. Identification of serum soluble ST2 as a novel heart failure biomarker. Circulation 2003;107:721-6.

34. Mildner M, Storka A, Lichtenauer M, et al. Primary sources and immunological prerequisites for ST2 secretion in humans. Cardiovasc Res 2010;87:769-77.

35. Bartunek J, Delrue L, van Durme F, et al. Non myocardial production of ST2 protein in human hypertrophy and failure is related to diastolic load. JACC 2008;52:2166-74.

36. Aoki S, Hayakawa M, Ozaki H, et al. ST2 gene expression is proliferation-dependent and its ligand, Il-33, induces inflammatory reaction in endothelial cells. Mol Cell Biochem 2010;335:75-81.

37. Shimpo M, Morrow DA, Weinberg EO, et al. Serum levels of the interleukin-1 receptor family member ST2 predicts mortality and clinical outcome in acute myocardial infarction. Circulation 2004;109:2186-90.

38. Sabatine MS, Morrow DA, Higgins LJ, et al. Complementary roles for biomarkers of biochemical;strain ST2 and N-terminal prohormone B-type natriuretic peptide in patients with ST-elevation myocardial infarction. Circulation 2008;117:1936-44.

39. Weir RA, Miller AM, Murphy LE, et al. Serum Soluble ST2: a potential novel mediator in left ventricular and infarct remodelling after acute myocardial infarction. JACC 2010;5 5:243-50.

40. Daniels LB, Clopton P, Iqbal N, et al. Association of ST2 levels with cardiac structure and function and mortality in outpatients. Am Heart J 2010;160:721-8.

41. Boisot S, Beede J, Isakson S, et al. Serial sampling of ST2 predicts 90-day mortality following destabilized heart failure. J Card Fail 2008;14:732-8.

42. Mueller T, Dieplinger B, Gegenhuber A, et al. Increased plasma concentrations of soluble ST2 are predictive for 1 -year mortality in patients with acute destabilized heart failure. Clin chem 2008;54:752-6.

43. Pascual-Figal DA, Ordonez-Llanos J, Tornel PL, et al. Soluble ST2 for predicting sudden cardiac death in patients with chronic heart failure and left ventricular systolic dysfunction. JACC 2009;54:2174-9.

44. Bayes-Genis A, Pascual-Figal D, Jannuzi JL, et al. Soluble ST2 monitoring provides additional risk stratification for outpatients with decompensated heart failure. Rev Esp Cardiol 2010;63:1171-8.

45. Januzzi JL, Peacock WF, Maisel AS, et al. Measurements of the inter-leukin family member ST2 in patients with acute dyspnoea: results from the PRIDE (pro-brain natriuretic peptide investigation of dyspnoea in the emergency department) study. JACC 2007;50:607-13.

46. Martinez-Rumayor A, Carmago CA, Green SM, et al. Soluble ST2 plasma concentrations predict 1-year mortality in acutely dyspnoeic emergency department patients with pulmonary disease. Am J Clin Pathol 2008;130:578-84.

47. Shah RV, Chen-Tournox AA, Picard MH, et al. Serum levels of interleukin-1 receptor family member ST2 cardiac structure and function and long-term mortality in patients with acute dypnoea. Circ Heart Fail 2009;2:311-9.

48. Wang YC, Yu CC, Chiu FC, et al. Soluble St2 as a biomarker for detecting stable heart failure with a normal ejection fraction in hypertensive patients. J Card Fail 2013;19:163-8.

49. Ho JE, Larson MG, Ghorbani A, et al. Soluble ST2 predicts elevated SBP in the community. J Hypertens 2013;31:1431-6.

50. Szerafin T, Niederpold T, Mangold A, et al. Secretion of soluble ST2-possible explanation for systemic immunosuppression after heart surgery. Thorac Cardiovasc Surg 2009;57:25-9.

51. Coglianese EE, Larson MG, Vasan RS, et al. Distribution and clinical correlates of the Interleukin Receptor Family Member Soluble ST2 in the Framingham Heart Study. Clinical Chemistry 2012;58:1673-81.

52. Ojji DB, Opie LH, Lecour S, et al. The effect of left ventricular remodelling on soluble ST2 in a cohort of hypertensive subjects. J Hum Hypertens 2014;28: 432-7. 
53. Ojji DB, Opie LH, Lecour S, et al. Relationship between left ventricular geometry and soluble ST2 in a cohort of hypertensive patients. J Clin Hypertens (Greenwich) 2013;15:899-904.

54. Wang W, Xu J, Kirsch T. Annexin-mediated ca2+ influx regulates growth plate chondrocyte maturation and apoptosis. J Biol Chem 2003;278:3762-69.

55. Konishi Y, Sato H, Tanaka T. Anisomycin super induces annexin $\mathrm{V}$ mRNA expression through the ERK1/2 but not the p38 MAP kinase pathway. Biochem Biophys Res Commun 2004;313:977-83.

56. Ravassa S, González A, López B, et al. Upregulation of myocardial Annexin A5 in hypertensive heart disease: association with systolic dysfunction. Eur Heart J 2007;28:2785-91.

57. Díez J, Panizo A, Gil MJ, et al. Serum markers of collagen type I metabolism in spontaneously hypertensive rats: relation to myocardial fibrosis. Circulation 1996;93:1026-32.

58. Querejeta R, Varo N, Loez B, et al. Serum carboxyterminal propeptide procollagen type $\mathrm{I}$ is a marker of myocardial fibrosis in hypertensive heart disease. Circulation 2000;101:1729-35.

59. López B, Querejeta R, Varo N, et al. Usefulness of serum carboxy-terminal propeptide of procollagen type I in assessment of the cardioreparative ability of antihypertensive treatment in hypertensive patients. Circulation 2001;104:286-91.

60. Díez J, Laviades C, Mayor G, et al. Increased serum concentrations of procollagen peptides in essential hypertension. Relation to cardiac alterations. Circulation 1995;91:1450-6.

61. McNulty M, Mahmud A, Spiers P, et al. Collagen type-I degradation is related to arterial stiffness in hypertensive and normotensive subjects. J Hum Hypertens 2006;20:867-73.

62. Querejeta R, Lopez B, Gonzalez A, et al. Increased collagen type 1 synthesis in patients with heart failure of hypertensive origin. Relation to myocardial fibrosis. Circulation 2004;110:1263-8.

63. López B, González A, Querejeta R, et al. Alterations in the pattern of collagen deposition may contribute to the deterioration of systolic function in hypertensive patients with heart failure. J Am Coll Cardiol 2006;48:89-96.

64. Maharaj N, Khandheria BJ, Libhaber E, et al. Relationship between left ventricular Twist and Circulating Biomarkers of Collagen Turnover in Hypertensive Patients with Heart Failure. J Am Soc Echocardiogr 2014;27:1064-71.

65. de Boer RA, Yu L, van Veldhuisen DJ. Galectin-3 in cardiac remodeling and heart failure. Curr Heart Fail Rep 2010;7:1-8.

66. Sharma UC, Pokharel S, van Brakel TJ, et al. Galectin-3 marks activated macrophages in failureprone hypertrophied hearts and contribute to cardiac dysfunction. Circulation 2004;110:3121-8.

67. Seferovic JP, Lalic NM, Floridi F, et al. Structural myocardial alterations in diabetes and hypertension: the role of galectin-3. Clin Chem Lab Med 2014;52:1499-505.

68. Sliwa K, Ojji D, Bachelier K, Damasceno A. Hypertension and hypertensive heart disease in African women. Clin Res Cardiol 2014;103:515-23.

69. Sliwa K, Bohm M. Incidence and prevalence of pregnancyrelated heart disease. Cardiovasc Res 2014;101:554-60.

70. Damasceno A, Mayosi BM, Sani M, et al. The causes, treatment, and outcome of acute heart failure in 1006 Africans from 9 countries. Arch Intern Med 2012;172:1386-94.
Cite this article as: Ojji D, Libhaber E, Lamont K, Thienemann F, Sliwa K. Circulating biomarkers in the early detection of hypertensive heart disease: usefulness in the developing world. Cardiovasc Diagn Ther 2020;10(2):296-304. doi: $10.21037 /$ cdt.2019.09.10 